\title{
The Relationship between Interaction and Audience Anxiety Levels and Internet Addiction of Adults
}

\author{
Ozgen Korkmaz, Cengiz Sahin, \& Ertugrul Usta \\ Ahi Evran University, Turkey
}

\begin{abstract}
The purpose of this study was to investigate the relationship between interaction and audience anxiety levels and Internet addiction of adults. The research was performed in the survey model as a descriptive study. A total of 384 adults with different ages living in a Central Anatolian city constituted the sample of the study. Data were collected through the Interaction and Audience Anxiety Scale $(\alpha=.91)$ and Internet Addiction Scale $(\alpha=.86)$. The mean, standard deviation, frequency, percentage, t-test, ANOVA, Scheffe test, and Pearson correlation coefficient were employed in analyzing the data $(p<.05)$. The following results were obtained: Both the interaction anxiety and audience anxiety levels of adults were low. The levels among adults in the ages of 20-29 were significantly higher than the levels among adults in other age-groups. The levels of interaction anxiety and audience anxiety in the student group were significantly higher than other occupational groups. Gender did not differentiate interaction and audience anxiety levels of adults. There was also a positive and significant correlation between the levels of anxiety and Internet addiction.
\end{abstract}

Keywords: Interaction anxiety; Audience anxiety; Internet addiction; Adults

\section{Introduction}

Humans, which are social beings, have to be in a constant interaction and communication with their surroundings. Coming across new people at almost every stage of their life, they use different channels of communication in new environments, which can sometimes complicate the communication process even more. In this relatively complex structure, individuals can be successful to the extent that they are able to communicate and interact well (Ozturk, 2004). While some individuals can express themselves easily, others experience communication problems and difficulties in communicating with their surroundings. This situation can turn into conflict or quarrels and make life insufferable for these people. It can be argued that, as often claimed, this situation is not true only for teenagers but also for adults. Although the term adult is interpreted in distinctive forms in many cultures, it is generally accepted as the period of life in which an individual reaches a level of maturity with regard to the biological, psychological and social areas of development and begins with puberty (Smith, 1996). This period generally starts around the age of 17-18 and incorporates a process extending to the death of the individual.

In general, adult education can be defined as the process of providing knowledge and skills to individuals who regard themselves as adult in terms of age and social role. They are also 
conscious of being responsible for their own life, in parallel to their interest and needs in daily or professional life (Merriam \& Brockett, 1996). When the respective literature is looked through, it is seen that adult education practices are mostly associated with the concepts of schooling and development. It is usually carried out in informal education institutions, such as businesses, continuing education practices at the level of secondary and higher education, institutions of distance education, vocational education courses and public education centers (Koc, Tas, Ozkan \& Yilmaz, 2009). In such modes of education, training in utilizing leisure time or improving dexterities is given. Interpersonal communication is something that requires close attention in the adult education process.

Interpersonal communication difficulties may have numerous reasons which can include those stemming from the individual and his/her surrounding. Social anxiety may be the most important of all these reasons (Ozturk, 2004). The environment is as effective as heredity in the shaping of social anxiety (Yuksel, 1995). Anxiety is a condition of being stimulated that manifests itself in the physical, emotional and mental changes that a person experiences when encountering a stimulant. Anxiety can be identified as an unpleasant emotional condition characterized by a feeling of the possibility of a danger to be faced, discomfort, tension and fear (Oktem, 1981). Once the intensity and persistence of anxiety increases, it appears as a problem for people (Cuceloglu, 1997). Normal levels of anxieties help individuals to desire, decide, produce energy in the direction of decisions taken, and in terms of using this energy to improve their performance; but if the anxiety that the individual experiences is quiet intense, then the efficient use of his/her energy, the direction of his/her focus and the power to do the work that he/she is required to do is hindered (Aydin \& Dilmac, 2004). According to Leary and Kowalski (1995), anxiety can be defined as an emotional condition in which the feeling of impotence that is perceived during preparation for a sensed danger is experienced.

Adults can experience various anxiety situations depending on both causes in the daily life process and stemming from workload. It can be argued that the anxieties experienced by adults arise from the lack of social skills; people feel anxious about stepping into social environments because they lack the necessary social skills. This situation affects individuals' lives and their accomplishments. Likewise, it can be said that the levels of perception of individuals with high social anxiety with respect to how they are perceived and assessed by others affect their anxiety level. In this case, individuals are motivated regarding the making of certain impressions on the people that they interact with (Ozturk, 2004).

Interpersonal interaction and relationships are separated into two aspects: dependent and independent. The social anxiety arising from dependent relationships is mostly related to shyness and shamefacedness (Ozturk, 2004). The term 'interaction anxiety' is used for social anxiety stemming from dependent relationships. On the other hand, the term 'audience anxiety' is generally used for social anxieties such as speaking anxiety, stage fright and performance anxiety that can be counted among the anxieties emerging from independent relationships (Leary, 1983). Human beings intend to establish a harmonious relationship with the social environment in which they live by communicating. When it is considered that the communication process, a social process, is a vital necessity, it can be argued that adult education is important in eliminating both social anxiety and interaction as well as various types of audience anxieties that are present in people or can emerge in the future. These anxieties generally depend on family and the form of upbringing (Bruch, Heimberg, Berger, \& Collins, 1989). This situation, which can result in negative attributes, harmful habits and 
addictions, can transform an individual into an adult with high anxiety levels who cannot establish a healthy relationship with others.

It is possible to talk about negative effects of computers and particularly the Internet such as having high levels of anxiety, being antisocial, and over-fondness for or dependence on anything that can be harmful, as well as their positive effects on individuals and society in the present day (Calik \& Cinar, 2009; Kelleci, 2008; Khasawneh \& Al-Awidi, 2008; Weiner, 1996). Internet addiction can be counted as one of these negative effects (Chou, Condron, \& Belland, 2005).

Internet addiction is a term that denotes the harmful and uncontrolled use of the Internet. In recent years, Internet addiction has begun to be dealt with as a psychological problem by relating to various psychological issues. In particular, educators, psychology consultants, psychologists and psychiatrists have turned towards various forms of research on the issue. The concept of Internet addiction, which began to be used in 1995 for the first time, has become associated with various terms in recent years, such as "net addiction", "Internet addiction", "online addiction", "Internet addiction disorder", "pathologic Internet use" and "cyber disorder" (Eichenberg \& Ott, 1999). Although Internet addiction does not yet have a standard definition (Chou, Condron, \& Belland, 2005), its most basic symptoms can be described as not being able to set a limit to Internet use, persisting in its use despite social or academic damage and feeling an intense anxiety when limiting access to the Internet (Ozturk, Odabasioglu, Eraslan, Genc, \& Kalyoncu, 2007).

Internet addiction is not still be defined as a disease by the "Diagnostic and Statistical Manual of Mental Disorders", published in 1994 by the American Psychiatric Association. It is referred to with the abbreviation of "DSM IV" (Arisoy, 2009). Pathological gambling is said to be the closest disorder to Internet addiction (Ozturk et al, 2007). Young, who first came up with the definition of Internet addiction and put forward the first diagnostic criteria, became convinced that "pathological gambling", which is included under the title of impulse control disorders in DSM IV, is the closest disorder to Internet addiction that does not involve the abuse of any substance (Greenfield, 1999; cited in Arisoy, 2009).

As a result, the lack of social skills and the anxiety people feel when participating in social environments due to their lack of social skills, can be argued as underlying interaction and audience anxiety. Considering the socialization problems that Internet addiction causes in individuals, it can be conceived that there might be a correlation between Internet addiction on the one hand and interaction and audience anxiety on the other.

If Internet addiction is considered one of the significant problems faced by modern societies, it is important to determine the causes of this addiction and what is needed to keep it under control. In this respect, determining the relationship between Internet addiction and interaction and audience anxiety is essential in terms of examining Internet addiction more closely. Internet addiction and the interaction and audience anxiety can be effective for an adult to lead a healthy life socially.

Starting from this premise, the purpose of this research was to identify the interaction and audience anxiety levels of adults, and to determine what kind of relationship exists between these and Internet addiction. The following questions were addressed: 
1. How serious are interaction anxiety and audience anxiety among adults?

2. Are the interaction anxiety and audience anxiety levels of adults differentiated in terms of the variables of age group, occupation, and gender?

3. Is there a relationship among Internet addiction, interaction anxiety, and audience anxiety levels of adults?

\section{Methods}

\section{Research Model}

This research was performed as a descriptive study. As well known, descriptive studies are intended to describe the situation of interest. In addition, this models aims to describe a current situation as it is with an objective approach (Karasar, 1999; Roscoe, 1975). In this sense, the present study attempted to identify what kind of a correlation exists between the Internet addiction and interaction7audience anxiety of adults.

\section{Study Group}

Adults who are at the age of 20 and above and living in the city center of Kirsehir constituted the research population. Simple random sampling, one of the various methods of random sampling, was employed for determining the study group. In order to be able to reach individuals of different age groups, the scale forms were distributed to university students to be answered both by themselves and by their parents, and also to elementary school and high school students to be answered by their parents. In addition, some scale forms were also given to two Internet cafes to be distributed among volunteers. A total of 1,300 scale forms were distributed in this way. However, only 621 forms were returned. Thus, 621 individuals at the age of 20 and above in Kirsehir city center constituted the study group of this research. However, 236 applicants among those individuals, who stated that they never used Internet, were excluded from the scope of the research. Thus, the study group consisted of 384 adults in total including 185 women and 199 men. The distribution of the study group with respect to age and occupation is summarized in Table 1.

Table 1. The Distribution of the Study Group with Respect to Age and Occupation Types

\begin{tabular}{lcccccc}
\hline Age Groups & Student & Worker & Unemployed & Housewife & Retired & Total \\
\hline $\mathbf{2 0 - 2 9}$ & 77 & 2 & 2 & 20 & 0 & 101 \\
$\mathbf{3 0 - 3 9}$ & 3 & 75 & 4 & 32 & 2 & 116 \\
$\mathbf{4 0 - 4 9}$ & 1 & 69 & 6 & 21 & 2 & 99 \\
$\mathbf{5 0}$ and over & 3 & 17 & 18 & 14 & 16 & 68 \\
\hline Total & 84 & 163 & 30 & 87 & 20 & 384 \\
\hline
\end{tabular}

\section{Data Collection Instrument}

"The Interaction and Audience Anxiety Scale" was used for measuring the interaction and audience anxiety levels of adults, and the "Internet Addiction Scale" was used for assessing their Internet addiction levels. "The Interaction and Audience Anxiety Scale", which was 
developed by Leary (1983) and adapted into Turkish by Ozturk (2004) by whom its validity and reliability studies were conducted, was employed to determine the social anxiety levels of adults. The original scale consisted of 27 items, including 15 for interaction anxiety and 12 for audience anxiety. Cronbach's Alpha value of the sub-scale of interaction anxiety was calculated as .82 and the Alpha value of the sub-scale of audience anxiety was calculated as .87 . Cronbach's Alpha value for the whole scale was calculated to be .91 .

The Internet addiction scale was employed, which was designed by Hahn and Jerusalem (2001) and intended for determining the Internet addiction levels of adults. Its original name was "Skala zur Erfassung der Internetsucht" and it was adapted into Turkish. The original scale developed by Hahn and Jerusalem consisted of 20 items in total and 5 factors as 4 questions for each factor. The internal consistency coefficient (Cronbach's Alpha) of the first factor, named "the Loss of Control", is .82. The internal consistency coefficient of the second factor is called "the Signs of Giving Up" and is .83. The internal consistency coefficient of the third factor is called "the Improvement of Tolerance" and is .81. The internal consistency coefficient of the fourth factor is called "the Negative Result in Study and Efficiency" and is .83. Finally, the internal consistency coefficient of the last factor is called "the Negative Results in Social Relationships" and is .82. The internal consistency coefficient for the whole scale is .93.

As a result of the adaptation study, the Internet addiction scale consisted of 19 items and 3 factors in the Turkish culture. First of all, Kaiser-Meyer-Oklin (KMO) and Bartlett test analyses were conducted on the data to test the structural validity of the scale and $\mathrm{KMO}=.919$, and the value of Bartlett test was identified as $x 2=6087.383 ; s d=171(p<, 000)$. It was stated that the items incorporated into the scale were amassed in three factors and the total variance explained its $68 \%$. As a result of the confirmatory factor analyses, it was determined that the model showed acceptable compatibility. Intended for estimating the distinctiveness power of items, correlations among scores attained from each item and scores acquired from factors were calculated and each item was detected to be in a significant and positive correlation with its factor score. Internal consistency analyses were carried out to estimate the reliability of the scale. Accordingly, internal consistency coefficients of factors were valued between .887 and .926 and the internal consistency coefficient for the scale in general is .858 .

\section{Data Analysis}

Each item in the interaction and audience anxiety scale was scaled as Not Reflecting at All (1), Reflecting Very Little (2), Partially Reflecting (3), Reflecting So Much (4) and Completely Reflecting (5). Due to the scale's structure, averages of the responses given by students to 5point Likert Type Scale for three sub-factors were calculated one by one. The increase in averages indicates that the Internet addiction level is high and the decrease in averages indicates that the addiction level is low. The scores obtained in response to answers given by individuals to 5-point Likert type scale do not display a standard characteristic owing to differences in the number of items in sub-factors. Hence, converting the obtained raw scores into standard scores in a way that the lowest one will be 20 point and the highest will be 100 was deemed suitable. The following formula can be utilized in conversion of raw scores into standard scores: 


$$
X_{\text {standardscore }}=\frac{\text { Xrawscore }}{\text { ArticleNumberofScale. }} \times 20
$$

The obtained point differences were divided into $5(100-20=80 / 5=16)$ and the point interval for levels were calculated. Since the scales used in the study were 5-point Likert type, their level intervals had to be equal (Balci, 1997) and the point totals given to each item in the scales were standardized between 20-100. According to this point interval, levels were determined as follows: 20-35: Very Low; 36-51: Low; 52-67: Medium; 68-83: High; 84-100: Very High. However, since the levels formed in this way are very little, it was found suitable to unite the levels of "Very Low" and "Low", and "High" and "Very High". At this frame, the levels corresponding to the scores obtained from sub-scales can be summarized as 20-51: Low interaction and audience anxiety; 52-67: Medium interaction and audience anxiety; 68-100: High interaction and audience anxiety.

In this respect, the interaction and audience anxiety levels of adults were examined by using the arithmetic average, standard deviation, t-test, ANOVA and Scheffe analyses. The correlation between interaction and audience anxieties and Internet addiction was examined via Pearson $r$ correlation analysis. The $p<.05$ level was found sufficient for the significance of inter-factor correlation.

\section{Results}

\section{Interaction and Audience Anxiety Levels of Adults}

The interaction and audience anxiety levels of adults as measured in the present study are summarized in Table 2.

Table 2. The Interaction and Anxiety Levels of Adults

\begin{tabular}{|c|c|c|c|c|c|c|c|c|c|c|c|}
\hline \multirow{3}{*}{$\frac{\text { Variables }}{\text { Interaction Anxiety }}$} & \multirow{2}{*}{$\mathbf{N}$} & \multirow{2}{*}{$\bar{X}$} & \multirow{2}{*}{ S.S } & \multirow{2}{*}{ Min } & \multirow{2}{*}{ Max } & \multicolumn{6}{|c|}{ Levels (f/\%) } \\
\hline & & & & & & \multicolumn{2}{|c|}{ Low } & \multicolumn{2}{|c|}{ Middle } & \multicolumn{2}{|c|}{ High } \\
\hline & 384 & 43.26 & 11.8 & 20.0 & 88.57 & 310 & 80.7 & 56 & 14.6 & 18 & 4.7 \\
\hline Audience Anxiety & 384 & 46.63 & 17.6 & 20.0 & 100.00 & 254 & 66.1 & 84 & 21.9 & 46 & 12.0 \\
\hline
\end{tabular}

As seen in Table 2, the interaction anxiety scores of adults varied between 20.00 and 88.57 and their average was 43.26. When the data regarding the interaction anxiety levels is examined, it is observed that only $4.7 \%$ of adults have high interaction anxiety, $14.6 \%$ of them have medium interaction anxiety, and $80.7 \%$ have low interaction anxiety. The audience anxiety scores of adults, on the other hand, varied between 20.00 and 100.00 ; its average is 46.63 . When the data regarding the audience anxiety levels is examined, it is observed that $12.0 \%$ of adults have high audience anxiety, $21.9 \%$ of them have medium audience anxiety, and $66.1 \%$ have low audience anxiety. According to these figures, it can be said that adults both have quite low interaction and audience anxiety levels but their audience anxiety levels are higher than interaction anxiety levels. 


\section{Interaction and Anxiety Levels of Adults According to the Variables of Age Group, Gender and Occupation}

The findings concerning the interaction and anxiety levels of adults with respect to age groups are summarized in Table 3.

Table 3. The Interaction and Anxiety Levels of Adults with Respect to Age Groups

\begin{tabular}{lccccc}
\hline \multirow{2}{*}{ Age Groups } & \multirow{2}{*}{$\mathbf{N}$} & \multicolumn{2}{c}{ Interaction Anxiety } & \multicolumn{2}{c}{ Audience Anxiety } \\
\cline { 3 - 6 } & & $\overline{\mathbf{x}}$ & $\mathbf{S s}$ & $\overline{\mathbf{x}}$ & $\mathbf{S s}$ \\
\hline $\mathbf{2 0 - 2 9}$ & 101 & 48.08 & 13.60 & 53.93 & 18.03 \\
$\mathbf{3 0 - 3 9}$ & 116 & 40.75 & 11.76 & 44.22 & 16.90 \\
$\mathbf{4 0 - 4 9}$ & 99 & 41.47 & 10.08 & 42.70 & 16.32 \\
$\mathbf{5 0}$ and over & 68 & 42.96 & 8.81 & 45.67 & 16.82 \\
Total & 384 & 43.26 & 11.76 & 46.64 & 17.56 \\
\hline
\end{tabular}

When Table 3 is examined, it is seen that the age group with the highest interaction and audience anxiety levels among adults is the 20-29. The age group with the lowest interaction anxiety levels is the 30-39, and the age group with the lowest audience anxiety levels is the 4049. The outcomes of variance analysis and the Scheffe test conducted in order to determine the effect of age group variable on the interaction and audience anxiety levels are summarized in Table 4.

Table 4. The Effect of Age Groups on the Interaction and Anxiety Levels of Adults

\begin{tabular}{|c|c|c|c|c|c|c|c|}
\hline & sv & SS & df & MS & $\mathbf{F}$ & $p$ & Scheffe \\
\hline $\begin{array}{l}\text { Interaction } \\
\text { Anxiety }\end{array}$ & $\begin{array}{l}\text { Between Groups } \\
\text { Within Groups } \\
\text { Total }\end{array}$ & $\begin{array}{r}3395.612 \\
49557.827 \\
52953.439\end{array}$ & $\begin{array}{r}3 \\
380 \\
383\end{array}$ & $\begin{array}{r}1131.871 \\
130.415\end{array}$ & 8.679 & .000 & $\begin{array}{l}\text { Between } 20-29 \text { age } \\
\text { group and others }\end{array}$ \\
\hline $\begin{array}{l}\text { Audience } \\
\text { Anxiety }\end{array}$ & $\begin{array}{l}\text { Between Groups } \\
\text { Within Groups } \\
\text { Total }\end{array}$ & $\begin{array}{r}7655.209 \\
110431.533 \\
118086.742\end{array}$ & $\begin{array}{r}3 \\
380 \\
383\end{array}$ & $\begin{array}{r}2551.736 \\
290.609\end{array}$ & 8.781 & .000 & $\begin{array}{l}\text { Between } 20-29 \text { age } \\
\text { group and others }\end{array}$ \\
\hline
\end{tabular}

As seen in Table 4, age groups of adults revealed a significant difference on both interaction and audience anxiety levels (Interaction: $F_{(3-380)}=8.679 ; p<.001$; Audience: $F_{(3-380)}=8.781$; $p<.001)$. According to the Scheffe analysis performed, the significant difference that age groups brought out on the interaction and audience anxiety levels stems from the 20-29 age group. The average of the 20-29 age group with regard to interaction anxiety levels is $\bar{X}=48.05$, the average regarding audience anxiety levels is $\bar{X}=59.93$. These averages are much lower in other age groups. According to these findings, it can be said that the interaction and audience anxiety levels of adults in the 20-29 age group are significantly higher compared to older age groups.

The second demographic variable, whose effect was investigated in the present study, was occupation of respondents. The findings regarding the interaction and audience anxiety levels of adults with respect to occupation groups are summarized in Table 5. 
Table 5. The Interaction and Anxiety Levels of Adults with Respect to Occupation Groups

\begin{tabular}{|c|c|c|c|c|c|}
\hline \multirow{2}{*}{ Occupation Groups } & \multirow{2}{*}{$\mathbf{N}$} & \multicolumn{2}{|c|}{ Interaction Anxiety } & \multicolumn{2}{|c|}{ Audience Anxiety } \\
\hline & & $\bar{x}$ & Ss & $\bar{x}$ & Ss \\
\hline Student & 84 & 49.86 & 13.30 & 56.90 & 18.32 \\
\hline Worker & 163 & 41.19 & 10.46 & 43.29 & 15.58 \\
\hline Unemployed & 30 & 41.71 & 8.75 & 42.73 & 16.344 \\
\hline Housewife & 87 & 41.49 & 11.44 & 45.68 & 16.88 \\
\hline Retired & 20 & 42.29 & 11.12 & 40.82 & 18.87 \\
\hline Total & 384 & 43.6 & 11.76 & 46.64 & 17.56 \\
\hline
\end{tabular}

When Table 5 is examined, it is seen that the group with the highest interaction and anxiety levels among adults is students. The group with the lowest anxiety level in terms of interaction anxiety is the employees group and the group with the lowest anxiety levels in terms of audience anxiety is the unemployed group. The outcomes of variance analysis and the Scheffe test carried out to detect the effect of occupation groups on the interaction and audience anxiety levels are summarized in Table 6.

Table 6. The Effect of Occupation Groups on the Interaction and Anxiety Levels of Adults

\begin{tabular}{|c|c|c|c|c|c|c|c|}
\hline & SV & SS & df & MS & $\mathbf{F}$ & $\mathbf{p}$ & Scheffe \\
\hline $\begin{array}{l}\text { Interaction } \\
\text { Anxiety }\end{array}$ & $\begin{array}{l}\text { Between Groups } \\
\text { Within Groups } \\
\text { Total }\end{array}$ & $\begin{array}{r}4722.455 \\
48230.983 \\
52953.439\end{array}$ & $\begin{array}{r}4 \\
379 \\
383 \\
\end{array}$ & $\begin{array}{r}1180.614 \\
127.259\end{array}$ & 9.277 & .000 & $\begin{array}{l}\text { Between students } \\
\text { and others }\end{array}$ \\
\hline $\begin{array}{l}\text { Audience } \\
\text { Anxiety }\end{array}$ & $\begin{array}{l}\text { Between Groups } \\
\text { Within Groups } \\
\text { Total }\end{array}$ & $\begin{array}{r}11895.923 \\
106190.820 \\
118086.742\end{array}$ & $\begin{array}{r}4 \\
379 \\
383\end{array}$ & $\begin{array}{r}2973.981 \\
280.187\end{array}$ & 10.614 & .000 & $\begin{array}{l}\text { Between students } \\
\text { and others }\end{array}$ \\
\hline
\end{tabular}

As seen in Table 6, occupation groups of adults revealed a significant differentiation on both interaction and audience anxiety levels (Interaction: $F_{(4-379)}=9.277 ; p<.001 ;$ Audience: $F_{(4-}$ $379)=10.614 ; p<.001)$. According to the Scheffe analysis performed, the significant difference that occupation groups brought out on the interaction and audience anxiety levels stems from the student group. The average of the student group with regard to interaction anxiety levels is $\bar{X}=49.86$, the average regarding audience anxiety levels is $\bar{X}=56.90$. These averages are much lower in other occupation groups. Accordingly, it can be argued that the interaction and audience anxiety levels of adults in the student group are significantly higher compared to other occupation groups.

Findings regarding the interaction and audience anxiety levels of adults with respect to gender are summarized in Table 7.

Table 7. The Effect of Gender on the Interaction and Anxiety Levels of Adults

\begin{tabular}{lccccccc}
\hline Variables & & $\mathbf{N}$ & $\bar{X}$ & Ss & $\mathbf{t}$ & sd & p \\
\hline \multirow{2}{*}{ Interaction Anxiety } & Female & 185 & 43.61 & 13.29 & .563 & 382 \\
& Male & 199 & 42.93 & 10.16 & .573 \\
\hline \multirow{2}{*}{ Audience Anxiety } & Female & 185 & 48.07 & 18.87 & 1.542 & 382 \\
& Male & 199 & 45.31 & 16.18 & .573 \\
\hline
\end{tabular}


As seen in Table 7, there is no significant difference between interaction and audience anxieties with respect to the gender of adults (Interaction: $t_{(1-382)}=0.563 ; p>.05$; Audience: $t_{(1-}$ $382)=1.542 ; p>.05)$. According to this, it can be stated that gender does not differentiate the interaction and audience anxiety levels of adults.

\section{Relationship between Interaction/Audience Anxiety and Internet Addiction}

The findings concerning the correlation between the interaction and audience anxiety levels and Internet addiction levels of adults are summarized in Table 8.

Table 8. The Relationship between the Interaction and Audience Anxiety Levels and Internet Addictions of Adults

\begin{tabular}{llcc}
\hline Internet Addictions & & $\begin{array}{c}\text { Interaction } \\
\text { Anxiety }\end{array}$ & $\begin{array}{c}\text { Audience } \\
\text { Anxiety }\end{array}$ \\
\hline Loss of control & Pearson $r$ & $.227\left(^{* *}\right)$ & $.219\left(^{* *}\right)$ \\
Desire to remain online more & Pearson $r$ & .032 & $.136\left(^{* *}\right)$ \\
Negativity in social relations & Pearson $r$ & .054 & $.151\left(^{* *}\right)$ \\
Total & Pearson $r$ & $.171\left(^{* *}\right)$ & $.265\left(^{* *}\right)$ \\
\hline
\end{tabular}

$\mathrm{N}=384 ;{ }^{*} \mathrm{p}<.05,{ }^{* *} \mathrm{p}<.01$.

When Table 8 is examined, although the extent of the relationship between the total scores of Internet addiction of adults and both their interaction $(r=.171, p<.01)$ and audience $(r=.265$, $p<.01)$ anxiety levels is low, there is a positive correlation at a significant level. When examined with respect to factors, there is a positive correlation at a significant level between the loss of control factor and both interaction $(r=.227, p<.01)$ and audience anxieties $(r=.219, p<.01)$; the factors of the desire to remain online more $(r=.136, p<.01)$ and negativity in social relations $(r=.151, p<.01)$ and audience anxiety levels. As a result, it can be argued that, as both interaction and audience anxiety levels increase, so do the Internet addiction levels of adults using the Internet.

\section{Discussion and Conclusion}

Both the interaction and audience anxiety levels of adults in this study were found to be quite low. However, their audience anxiety levels are higher than interaction anxiety levels. Based on this finding, it can be said that individuals consider themselves socially skilful and their social interaction anxieties fall accordingly. The existence of many variables that can affect social anxiety, both directly and indirectly, can be mentioned. One of them is the social environment where people live in. It can be asserted that the physical nature and population of a social environment can be essential in the anxiety levels of people and may affect an individual's strategies to present himself/herself to the society. As a matter of fact, the city where research was carried out can be regarded as a small social environment. Owing to the fact that people can constantly see each other in limited and small social environments, they experience "visual acquaintance" and do not consider themselves strangers to each other so that they can interact in a quite comfortable fashion. Likewise, the fears of "I may make a mistake" or "it will be inappropriate" can be high due to this visual acquaintance. This situation can increase audience anxiety levels. 
The research conducted by Leary (1995) seems to support this finding. According to Leary, human beings tend to make a better impression on others in social context or environment. Similarly, if there are negative attributes such as the anxiety to be favored by society, insecurity and narcissism, an individual's strategies to present himself/herself are effective in eliminating them. By using these strategies, individuals try to leave the positive impression they desire on society. In Sanz and Grana's (1994) research conducted in Spain, they inferred that in case of individual act, affected by expectations of social environment, they become shy individuals with low self-respect. On the other hand, the ones who live at peace with social life become more social individuals with higher self-respect.

The interaction and audience anxiety levels of adults between the ages of 20-29 are significantly higher than the interaction and audience anxiety levels of other adults older than 29. It appears that there exists a correlation between the social status that people possess and anxiety levels. When it is considered that, in general, the 20-29 age group consists of university students or young adults who have just begun to work or make an effort to become firmly established in their occupation, anxiety over the future and the existence of fears that can develop accordingly may be important in interpersonal relationships. It can be argued that individuals aged 29 or over are generally adults who have started to work, got married and got their life in order, and fewer uncertainties apply in these individuals' lives compared to younger individuals. Thus, Pontari and Schlenker (2000) put forward similar outcomes in their study. The anxiety levels of people who have a job turned out to be lower than people with no job. Individuals display introverted behavior as their activities decrease and demonstrate extroverted behavior as their activity increases in settings of interpersonal communication. The emergence of this situation could stem from the fact that these adults, aged 29 and above, generally have a job.

The interaction and audience anxiety levels of adults in the student group are significantly higher than other occupation groups when looked at with respect to professions. As also explained above, this finding puts forward the significance of experiencing future anxiety in interpersonal communication. Alongside experiencing future anxiety, the fear of negative evaluation by others could result in the increase of interaction and audience anxiety levels. In other words, it can be said that the fear of negative evaluation that university students have may result in interaction and audience anxieties. Therefore, Ozturk (2004) reported similar outcomes in his study and emphasized that teenagers' fear of negative evaluation may lead to social anxiety in them.

The gender factor does not differentiate the interaction and audience anxiety levels of adults. The gender factor can throw up different results in the respective literature in terms of social anxiety. As a matter of fact, Oztas (1996) and Gumus (1997) found in the studies they performed that social anxiety levels do not differentiate according to gender. It is also possible to come across research where the gender factor differentiates social anxiety. Palanci and Ozbay (2003) attempted to explain social anxieties that university students experienced via distinct variables; and as a result of their research, it was found that they were higher but not in favor of men.

There is a positive correlation at a significant level between the interaction and audience anxiety levels and Internet addiction. In other words, as both interaction and audience anxiety levels increase, the Internet addiction levels of adults using the Internet increase as well. Due 
to the fact that interaction and audience anxieties hinder adults in establishing face to face communication in their social life, these individuals prefer establishing relationships over the Internet more by hiding their identities and personalities, as maybe a different individual might have resulted in that these individuals became addicted to the Internet in time. Arisoy (2009) states that epidemiological research carried out regarding Internet addiction suggested that $50 \%$ of Internet addicts also have another psychiatric disorder.

\section{Recommendations}

When it is taken into consideration that the interaction and audience anxiety levels of adults between the ages of 20-29 are higher than in other adults and that there is also a positive correlation between these anxiety levels and Internet addiction, it can be said that it is necessary to take both social precautions and guidance precautions directed at decreasing the future anxieties experienced, especially by the individuals who have just started their adult lives. Within this framework, it can be suggested that universities establish units directed to watching their students and to providing both professional and psychological guidance after graduation. In addition to this, it can be suggested to establish similar units within the Ministry of Labor and Social Security.

Given the possible negative influences of interaction and audience anxiety levels and of Internet addiction on both individuals and society, new studies should be conducted in which different demographic variables and educational interventions are applied in order to explore these two important concepts better. Also, new studies should be conducted to make crosscultural comparisons among different societies.

\section{References}

Arisoy, O. (2009). Internet addiction and its treatment. Current Approaches in Psychiatry, 1(1), 55-67.

Aydin E. \& Dilmac, B. (2004). Matematik kaygisi [Math anxiety]. In M. Gurse (Ed.), Egitime ilişkin cesitlemeler. Konya: Egitim.

Bruch, M. A. Heimberg, R. G, Berger, P., \& Collins, T. M. (1989). Social phobia and perceptions of early parental and personal characteristics. Anxiety Research, 2, 57-65.

Chou, C., Condron, L., \& Belland, J. C. (2005). A review of the research on Internet addiction. Educational Psychology Review, 17(4), 363-388.

Cuceloglu, D. (1997). Insan ve davranisi [Human and its behavior]. ( $7^{\text {th }}$ edition). Istanbul: Remzi.

Calik, D. \& Cinar, O. P. (2009, Aralik). Gecmisten gunumuze bilgi yaklasimlari, bilgi toplumu ve Internet [Information approaches, information society and the Internet from past to present]. XIV.Conference of Internet in Turkey, Istanbul: Bilgi Universitesi.

Eichenberg, C. \& Ott, R. (1999). Internetabhängigkeit: Massenphänomen oder erfindung der medien? 19, 106-111. Retrieved 9 February 2011 from http://www.heise.de/ct/99/19/ 106/

Ellis, R. (1994). The study of second language acquisition. Oxford: Oxford University Press. 
Greenfield D. N. (1999). Psychological characters of compulsive Internet use: A preliminary analysis. Cyberpsychology Behavior, 2, 403-412.

Gumus, A. (1997). Universite ogrencilerinin sosyal kaygi duzeylerinin cesitli degiskenlere gore incelenmesi [An Examination of social anxiety levels of university students according to various variables]. Unpublished master's thesis. Ankara: Gazi University.

Hahn, A. \& Jerusalem, M. (2001). Internetsucht: Reliabilität und validität in der onlineforschung. Retrieved 14 February 142011 from http://psilab.educat.hu-berlin.de/ssi/ publikationen/Internetsucht_onlineforschung_2001b.pdf

Kelleci, M. (2008).The effects of Internet use, cell phones and computer games on mental health of children and adolescents. TAF Preventive Medicine Bulletin, 7(3),253-256.

Khasawneh, O. M. \& Al-Awidi, H. M. (2008). The effect of home computer use on Jordanian children: A Parental Perspective. Journal of Educational Computing Research. 39(3), 267-284.

Koc, M., Tas, S., Ozkan, H.H., \& Yilmaz E. (2009). Turkiye'de yetiskin ve yasam boyu egitime yonelik lisans program onerisi [An undergraduate program proposal for adult and lifelong education in Turkey]. Retrieved 27 February 2011 from http://oc.eab.org.tr/ egtconf/pdfkitap/pdf/339.pdf

Leary, M. (1995). Self-presentation: Impression management and interpersonal behavior. Wisconsin: Brown \& Benchmark.

Leary, M.(1983). Social anxiousness: The construct and its measurement. Journal of Personality, 47, 66-75

Merriam, S. B. \& Brockett, R. G. (1996).The profession and practice of adult education. San Francisco, CA: Jossey-Bass.

Oktem, O. (1981). Anksiyetenin ogrenmeye ve hafizaya etkisi [Effect of anxiety in learning and memory]. Istanbul: Guryay.

Oztas, T.(1996). A cross-cultural study of social anxiety in university student. Unpublished master's thesis. Istanbul. Bogazici University.

Ozturk, A. (2004). Sosyal kaygiya ilişkin kendini sunma modeli [The self-presentation model of social anxiety]. Yayinlanmamis doktora tezi. Ankara: Gazi Universitesi.

Ozturk, O., Odabasioglu, G., Eraslan, D., Genc Y., \& Kalyoncu, O. A. (2007). Internet addiction: Clinical aspects and treatment strategies. Journal of Dependence, 8, 36-41.

Palanci, M. \& Y. Ozbay. (2003, Eylul). Universite ogrencilerinde sosyal anksiyetenin kontrol algisi, sosyal ozyeterlik, incinebilirlik ve basacikma davranislari ile yordanabilirliği [Control perception of social anxiety in university students, predictability of injury of social self-efficacy and coping behavior]. 7th Congress of National Counseling and Guidance. Malatya.

Pontari, B.A. \& Schlenker, B.R. (2000). The influence of cognitive load on self- presentation can cognitive busyness help as well as harm social performance. Journal of Personality and Social Psychology, 78(6), 1092-1108.

Sanz, J. \& Grana, J.L. (1994). Auto observacion en adolescentes: Los problemas de la escales de auto- observacion de synder en poblacones no adultas. Anuario de Psicologia, 60, 63-79. 
Smith, M. K. (1996). Adult education. Retrieved 12 March 2011 from http://www.infed.org/ lifelong learning/badedgn.htm

Weiner, R. G. (1996). The Internet culture: Transitions and problems. ERIC Number: ED401898. Retrieved 24 March 2011 from http://www.eric.ed.gov/PDFS/ED401898.pdf

Yuksel, N. (1995). Ruhsal hastaliklar [Mental disorders]. Ankara: Hatipoglu.

Correspondence: Ozgen Korkmaz, Asistant Professor, Department of Computer Education and Instructional Technologies, Faculty of Education, Ahi Evran University, Kirsehir, Turkey 